Brian Detlor

McMaster University

Hamilton, Ontario, Canada

Heidi Julien

SUNY University at Buffalo

Buffalo, New York, USA

\title{
UNDERSTANDING DIGITAL LITERACY TRAINING SUCCESS: AN EXPLORATION ACROSS CANADA (Paper)
}

\begin{abstract}
This paper reports progress of a SSHRC-funded research investigation that studies the factors affecting the success of digital literacy skills training offered by community-led organizations, such as public libraries, across Canada. The goal of the study is to identify best practices. The study also seeks to contribute to the theoretical understanding of digital literacy instruction led by community organizations. This paper reports preliminary results of the analysis of interviews with administrators and instructors from organizations in Canada which offer such training, as well as from interviews and surveys collected from people who took part in these organizations' training activities.
\end{abstract}

\section{Introduction}

The study explores three areas of investigation: i) organizational factors that foster or challenge digital literacy initiatives led by public libraries and other community organizations; ii) user considerations that influence community member uptake of these initiatives, lead to gains in digital literacy skills development, and foster greater digital literacy appreciation among community members; and iii) performance measures that effectively evaluate digital literacy initiatives led by public libraries and community organizations.

The study, being undertaken by scholars across multiple disciplines, and supported by partners in the public library sector and other community organizations across Canada, builds knowledge and understanding from interdisciplinary and inter-institutional perspectives (i.e., library and information studies, information systems, social science, and business).

Digital literacy is the set of skills, knowledge and attitudes required to access, create, use, and evaluate digital information effectively, efficiently, and ethically (Julien, 2018). It is the ability of people to locate, organize, understand, evaluate and create information using digital technology (Bawden, 2001; Gilster, 1997). Digital literacy comprises two sets of broad skills: i) skills to operate and utilize digital technologies such as computers, tablets and smart phones; and ii) skills to access, create, use, and evaluate digital information (Detlor, 2018). As the world becomes more digital, it is essential that individuals become more digitally literate to fully participate and thrive in today's digital economy and use the Internet safely and effectively in daily life. Being digitally literate leads to more positive health outcomes (as people are more able to access high quality health information online), better access to government services, 
participative governance, workforce development (improved job performance, employment), and bridging of the digital divide (Julien, 2018). Canadian public libraries play an important role in digital literacy promotion in the communities they serve. These institutions have developed and delivered digital literacy programs to all Canadians, (including under-represented groups), and have been providing safe, secure and effective Internet and computer use since the advent of the World Wide Web (Julien \& Hoffman, 2008; Julien \& Breu, 2005). Examples of such community-based programs offered by Canadian public libraries include training in basic computer skills, email use, mobile device use, software operation (e.g., Word for Windows and Google), Web resource use, access to library and government electronic resources, Internet safety, digital privacy, social media use, job search skills, business research skills, and computer programming. Providing these programs is now a core public library service (Cole \& Ryan, 2016; Takala, 2018), as well as a service offered by a range of other community-based organizations, such as the YWCA, local industry education councils, community colleges, municipal information and community service departments, boards of education, city social planning and research councils, and small business enterprise centres.

There is recent evidence that such programs delivered by public libraries in Canada promote digital literacy, increase digital comfort, and encourage the adoption and use of digital technologies (Nordicity, 2018). However, there is a need for comprehensive performance measures that assess the effectiveness of digital literacy initiatives. Current performance measurement approaches for libraries, such as the Public Library Administration's Study Outcomes Toolkit and the Edge Toolkit developed by a coalition of 12 US library and government associations, are useful, but do not provide a comprehensive, research-based approach to evaluating the effectiveness of digital literacy programs. Complimentary standardized performance measures (i.e., input, output and outcome measures) for digital literacy initiatives that provide a common language and a common set of evaluation tools are needed as part of a National Digital Literacy Strategy for Canada (Takala, 2018). Standardized digital literacy performance measures will allow a library or other community-based organization to compare the results of its digital literacy initiatives with others at regional, provincial and national levels. These measures should be both quantitative and qualitative in nature, and assess both organizational factors and user considerations.

\section{Research Questions}

The focus of this study is to explore how to provide effective digital literacy initiatives led by public libraries and other community-based organizations in Canada, how to promote those initiatives effectively, and how to evaluate those initiatives. The study is investigating the following high-level research question: How can public libraries and other community-based organizations in Canada best deliver and evaluate the digital literacy initiatives they provide to the communities they serve? Secondary research questions include the following:

- What organizational factors foster or challenge digital literacy initiatives led by public libraries and other community organizations in Canada? 
- What user considerations concerning these digital literacy initiatives influence community member uptake, lead to gains in digital literacy skills development, and foster greater digital literacy appreciation among community members?

- What performance measures (i.e., input, output and outcome measures) should be used to effectively evaluate these digital literacy initiatives?

\section{Data Collection and Analysis}

Currently, the study comprises case studies of digital literacy activities conducted at two large public libraries and five community organizations in Canada. Subsequent data collection and analysis will include a national survey of public libraries across Canada. Together, the analysis of the survey and case studies will lead to greater understanding of the organizational factors and user considerations affecting digital literacy initiatives offered by public libraries and by other community organizations, and also greater understanding of the evaluation mechanisms (performance measures) used and needed to assess those initiatives.

Constructivist grounded theory (Charmaz, 2014) is serving as the underlying methodological approach. Grounded theory data analysis procedures, such as the flip-flop technique, use of constant comparisons, and the coding paradigm tool (Strauss \& Corbin 1990, Corbin and Strauss 2015) are being applied to identify categories and relationships between categories in the data, and identify a key category around which all other categories relate. The goal is to produce central process-oriented storylines that answer the study's research questions. Conceptual frameworks guiding the study design, data collection and initial data analysis include Activity Theory (Engestrom, 1987; Leont’ev, 1981; Vygotsky, 1978), which is being used as a conceptual framework to collect and analyze data concerning organizational factors affecting the implementation and rollout of digital literacy initiatives. Here, digital literacy initiatives are being treated as specific activities, and Activity Theory is being used to explore congruencies and contradictions surrounding these activities. In addition, Detlor et al.'s (2011) model of Information Literacy Instruction Factors Affecting Student Learning Outcomes and Serenko et al.'s (2012) model of Student Learning Outcomes of Information Literacy Instruction are being used to collect and analyze data concerning user considerations that influence: i) community member uptake, ii) gains in digital literacy skills development, and iii) greater digital literacy appreciation among community members. Kaplan \& Norton’s (1996) Balance Scorecard method will be used to identify and understand Key Performance Indicators involved in digital literacy initiatives, and to explore various input, output and outcome performance measures that could be used to assess the extent to which the strategic goals and objectives of the digital literacy initiatives are being met.

One-on-one open-ended interviews with staff responsible for the delivery and evaluation of digital literacy initiatives offered through public libraries and community organizations, and interviews/surveys with those who took part in the training have been completed. All interviews were audio-recorded and transcribed. In addition, documents pertaining to digital literacy initiatives at each case study site were collected and analyzed. To date, we have conducted interviews with 15 administrators, 6 instructors, and 24 local community members who took part in the training sessions observed. Analysis of these data will be reported at CAIS/ACSI 2020. 
Following the CAIS conference, a national survey to public libraries across Canada will be conducted to: i) capture a national picture of the variety and range of digital literacy initiatives underway at Canadian public libraries; ii) understand the organizational factors that foster or challenge digital literacy initiatives; iii) gain insight into user considerations that impact community member uptake, digital literacy skills development, and digital literacy appreciation; and iv) ascertain the extent and effectiveness of performance measures currently used by libraries to evaluate digital literacy initiatives.

Once results from the nation-wide survey and case studies are finalized, findings will be triangulated to produce a digital literacy initiative evaluation toolkit. This toolkit will incorporate performance measures that assess organizational factors and user considerations important to the successful delivery of digital literacy initiatives in public libraries and other community organizations. Three public libraries across Canada will then be selected to test the efficacy of the toolkit based on the feedback received from the national survey.

\section{References}

Bawden, D. (2001). Information and digital literacies: A review of concepts. Journal of Documentation, 57(2), 218-259.

Charmaz, K. (2014). Constructing Grounded Theory. $2^{\text {nd }}$ Ed., Sage: Thousand Oaks, California, USA.

Cole, B. \& Ryan, P. (2016). Public Libraries. In Being Evidence Based in Library and Information Practice. Koufogiannakis, D. \& Brettle, A. (Eds.). London, UK: Facet Publishing.

Corbin, J. \& Strauss, A. (2015). Basics of Qualitative Research: Techniques and Procedures for Developing Grounded Theory, 4th Edition, Sage: Los Angeles, USA.

Detlor, B., Julien, H., Willson, R., Serenko, A., \& Lavallee, M. (2011). Learning outcomes of information literacy instruction at business schools, Journal of the Association for Information Science and Technology, 62(3), 572-585.

Detlor, B. (2018). Invited speaker. Promoting Digital Literacy in the Community: A Social Lab Approach, May 4, Institute for Informatics and Digital Innovation, Edinburgh Napier University, Edinburgh, Scotland.

Engestrom, Y. (1987). Learning by Expanding: An Activity-Theoretical Approach to Developmental Research, Orienta-Konsultit: Helsinki, Finland.

Gilster, P. (1997). Digital Literacy. Wiley, New York.

Julien, H. (2018). Digital Literacy in Theory and Practice. In Encyclopedia of Information Science and Technology, Fourth Edition, (2243-2252). Khosrow-Pour, M. (Ed.). Hershey, PA: IGI Global. 
Julien, H., \& Breu, R. (2005). Instructional practices in Canadian public libraries. Library \& Information Science Research, 27(3), 281-301.

Julien, H., \& Hoffman, C. (2008). Information literacy training in Canada's public libraries. Library Quarterly, 78(1), 19-41. One of LQ’s top 20 most accessed articles.

Kaplan, R. S., \& Norton, D. P. (1996). Using the balanced scorecard as a strategic management system, Harvard Business Review, 76(1), 75-85.

Leont'ev, A.N. (1981), Problems of the Development of the Mind, Progress Publishers: Moscow, Russia.

Nordicity (2018). Technology Access in Public Libraries: Outcomes and Impacts for Ontario Communities. Available at https://www.torontopubliclibrary.ca/content/bridge/pdfs/nordicityfull- report.pdf. Last accessed, October 13, 2018.

Serenko, A., Detlor, B., Julien, H., \& Booker, L. (2012). A model of student learning outcomes of information literacy instruction in a business school, Journal of the American Society for Information Science and Technology, 63(4), 671-686

Strauss, A., \& Corbin, J. (1990). Basics of Qualitative Research: Grounded Theory Procedures and Techniques. Sage: Los Angeles, USA.

Takala, P. (2018). Confidential briefing to the Canadian Federation of Library Associations (CFLA) Board from the Chair of the Canadian Urban Libraries Council, March 27th.

Vygotsky, L. (1978). Mind in Society: The Development of Higher Psychological Processes, Harvard University Press: Cambridge, USA. 